\title{
Does Social Inequality Stimulate the Economic Growth? (On the examples of the chosen developing countries)
}

\author{
Alina Pukhaeva ${ }^{1}$, Elena Miroshina (Silantieva) ${ }^{2}$ \\ Financial University
}

\begin{abstract}
${ }^{1}$ International Finance Faculty, Financial University, Moscow; alexandra.puhaeva@gmail.com ${ }^{2}$ Ph.D. in economics, Associate Professor, Department of World Economy and International Finance, Financial University, Moscow; EAsila@yandex.ru
\end{abstract}

\section{Abstract}

The article critically examines the concept of social inequality, and suggests ways to determine it against the background of a wide range of factors that determine inequality among the richest and poorest countries. It also summarizes the inequalities between the three groups of countries by comparing some macroeconomic indicators of socio-economic inequality. We then checked for a linear relationship between the two quantitative variables. Using World Bank data and Reports of the United Nations on human development, we conducted an analysis of individual countries taken from three groups of countries (a total of thirty countries), for the period from 1990 to 2017. After a statistical analysis, we proved that inequality slows down economic growth.

Keywords: Inequality, income, GDP per capita, poverty, HDI

JEL classification: I31, J11, J24, D63

\section{Literature Review}

It is a common knowledge that the modern world in which we live is unfair and unequal. In general, inequality is regarded to be socio-economic, which in terms means that it is based on income. However, this is not a single measure of inequality but it is rather closely associated with social inequality. Researchers agreed to define social inequalities as differences in income, resources and status within and between individuals. These inequalities are maintained by those in power mostly via institutions. Differences in income distribution matter for a number of reasons, due to the fact that they truly reflect social injustice as well as represent the levels of happiness, according to Ortiz and Cummins (2011).

Despite the ongoing debates within the literature, there is a common belief that global inequality exists and that there are groups across the world that hold more wealth than others and those groups who live in poverty. There is numerous available and descriptive statistical data that presents vast income inequalities across the world, most of them can be found on some official reports of United Nations.

Inequality among people across the world is clearly presentable and is shown in numerous datasets. Thereafter, there is a common knowledge among scientists that inequality in the worldwide scale is vast. However, according to the Milanovic (2007), the way in which inequality is traveling is under the dispute. Based on the report of United Nations (2008) some researchers state that global inequality has been increasing in the past decades both nationally and internationally, with the increasing number of people living in countries in which income differentials are on rise. Interestingly, these increases are not all associated with high-income countries as the current trend is directed toward rising inequality within countries (Firebaugh, 2004). By contrast, other sources of data based on reports of United Nations (2009) depicts that living standards are increasing in some countries and poverty is decreasing as well. According to Milanovic (2010), measurement problems abound, assumptions may be made when 
Table 1

Global comparisons in inequality measures for the year of 2015

\begin{tabular}{cccc}
\hline Country & $\begin{array}{c}\text { Human Development } \\
\text { Index (HDI) values }\end{array}$ & $\begin{array}{c}\text { Education levels } \\
\text { (measured by school } \\
\text { enrollment ratio) }\end{array}$ & $\begin{array}{c}\text { GNI per capita, 2015 PPP } \\
\text { (US dollars) }\end{array}$ \\
\hline Austria & 0.893 & 100.02 & 43,609 \\
Norway & 0.949 & 112.99 & 67,614 \\
United Kingdom & 0.91 & 127.81 & 37,931 \\
China & 0.738 & 94.29 & 13,345 \\
Turkey & 0.767 & 102.49 & 18,705 \\
Mexico & 0.762 & 90.55 & 16,383 \\
Mali & 0.442 & 41.31 & 2,218 \\
Madagascar & 0.512 & 38.44 & 1,320 \\
Uganda & 0.493 & 23.24 & 1,670 \\
\hline
\end{tabular}

Source: Compiled by the authors on the basis of the data of Human Development Reports (http://hdr.undp.org/en) and World Bank dataset (https://data.worldbank.org).

calculations are being done and the selection of some countries within the measurement of overall datasets and trends also seem to skew and distort the larger picture.

The most important question for us is: how to measure social inequality and on the basis of some absolute values do analysis? By looking at opinions of different authors, I have summarized several methods of calculating it. First, according to Milanovic (2007), socio-economic inequality can be measured by comparing the average incomes of different countries. However, this approach, obviously, fails to measure inequality within countries. Second, global inequality can be measured in terms of individual incomes. Again, this is very meticulous work as it involves carrying out surveys, and, thus, is considered to be problematic and quite inaccurate. Third, the most appropriate and accurate method of measuring social inequality from my point of view, is the Human Development Index (HDI), which takes into account three dimensions: Health, Education and Living standards.

\section{Overview of the Global Comparisons in Inequality}

Let's conduct the analysis of global comparisons in inequality measures based on the measurement scales of selected countries. According to figures of the World Population Ageing report by the United Nations (2015), there is a distinct depiction of large disparities and, subsequently,

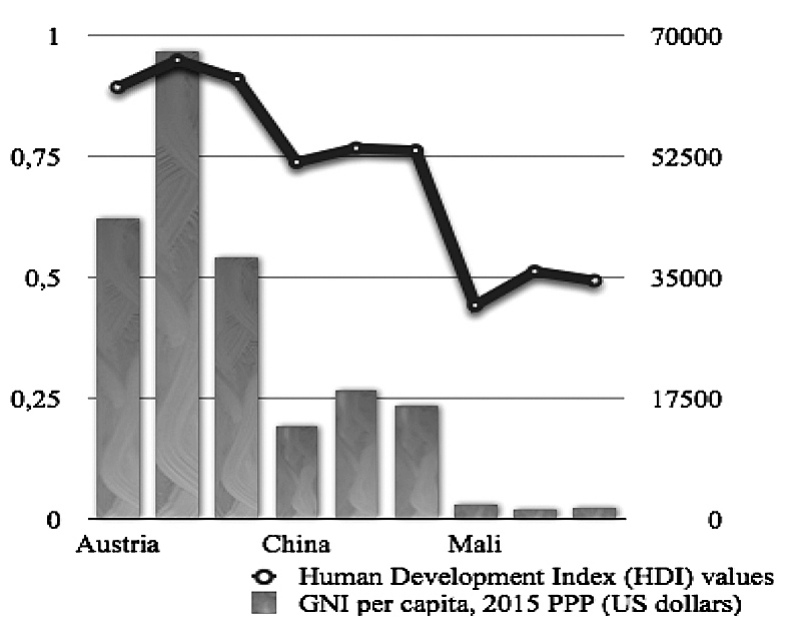

Figure 1. Trends in global comparisons in inequality measures in 2015.

inequality among many countries based on variety of metrics. Table 1 presents some of these inequalities. Due to the availability of the data, we considered only a period of 2015 instead of 2016 or 2017.

Based on the analytical data presented in Table 1, we can state that the figures of Human Development Index (HDI) are monotonically decreasing with respect to the level of development of countries and are positively associated with values of GNI per capita. Thus, for the high-income countries i.e., Austria, Norway and the UK, values of HDI were approximately 0.92 in 2015 since this category of countries are regarded to be highly developed. The average coefficient of HDI would be expected to be equal to unity if the countries 
Table 2

Poorest and richest in the world in 2016, measured according to GDP (US dollars)

\begin{tabular}{cccc}
\hline Poorest country & GDP per capita & Richest country & GDP per capita \\
\hline Mali & 779.9 & Luxembourg & $100,573.1$ \\
Burundi & 285.7 & Austria & $44,676.4$ \\
Mozambique & 382.1 & Oatar & $59,324.3$ \\
Niger & 364.2 & Denmark & $53,549.7$ \\
Uganda & 580.4 & Norway & $70,911.8$ \\
\hline
\end{tabular}

Source: Compiled by the authors on the basis of the data of the World Bank dataset (https://data.worldbank.org).

were perfectly developed. Smaller-income countries such as China, Turkey and Mexico, exhibited lower figures of HDI reflecting the fact that they yield smaller average of 0.76 and are regarded as developing countries. As for the countries of the third world (Mali, Madagascar and Uganda), the values of HDI are the lowest and account for only an average of 0.48 . This is the result of two factors: countries of the third world are associated with low development capacity of human beings and reflect shortage of capital.

With regard to Education Levels measured by school enrollment ratios, they also show monotonically decreasing pattern. Because of the fact that education levels are measured by school enrollment ratios, the average coefficient of it may not be expected to equal one hundred. In particular, since it may reflect late enrollment as well as early enrollment and repetition, the total enrollment could be expected to exceed the population of the age group which correspond to the official level of education-resulting in ratios greater than 100 per cent. Overall, the relation between high-income countries and school enrollment ratios is clearcut and allows to state that high coefficients of enrollment ratios are associated with high levels of HDI and GNI per capita. The average ratio of school enrollment for high income countries i.e., Austria, Norway and UK, accounts for 113.6 and a little bit less for countries such as China, Turkey and Mexico yielding an approximate figure of 95.78. By contrast, the poorest countries (Mali, Madagascar and Uganda) demonstrate that enrollment ratios are much lower compared to those of developed countries and are equal to an average of 34.33.

\section{Measuring Global Income Inequality}

Before proceeding to the examining global income inequality, it is important to consider the point of view of Sen (1999) regarding measuring inequality. He outlines that standards of living are important and play a crucial role in measuring this figure. This approach is connected to the poverty as well as justice and freedom. However, in his empirical work there are measurement errors, which he pointed out, related to the correct evaluation of the standards of living. Thus, in order to solve them out, indicators of social inequality such as gender, hunger and development were taken into consideration and included in the regression analysis of his empirical work. Another indicator of the degree of development is said to be well-being as high-income countries do not always signify the highest level of inequality.

According to Ortiz and Cummins (2011), it is possible to examine global income inequality based on Gross Domestic Product in absolute values, comparing the poorest and richest countries in order to show the severity of current global inequality based on the selection of several countries and presented in Table 2.

Based on the data extracted from World Bank dataset and presented in Table 2, it is straightforward to suggest a possible view point that GDP per capita measured in US dollars is a further demonstration of the level of inequality experienced today as the table demonstrates. Those countries with the highest levels of poverty are located on the left hand-side, according to 2015 measures, and the richest countries on the right hand-side. The table illustrates some interesting features by comparing the amounts of GDP per capita in two different groups of countries with regard to the level of development, demonstrating that low-income countries are associated with low economic growth and, vice versa, demonstrates that economic progress has been made in high- 


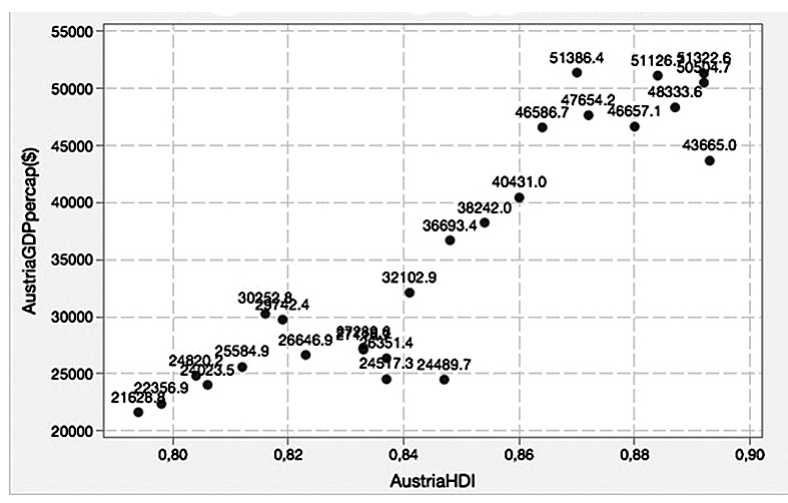

A1(a) Scatterplot of Austria GDP per capita (\$) vs Austria HDI

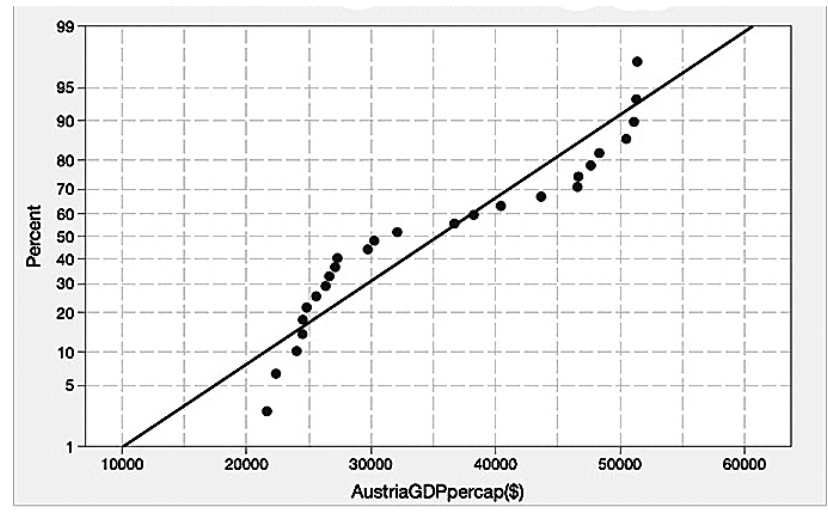

A1(c) Normal Probability Plot of Austria GDP per capita (\$)

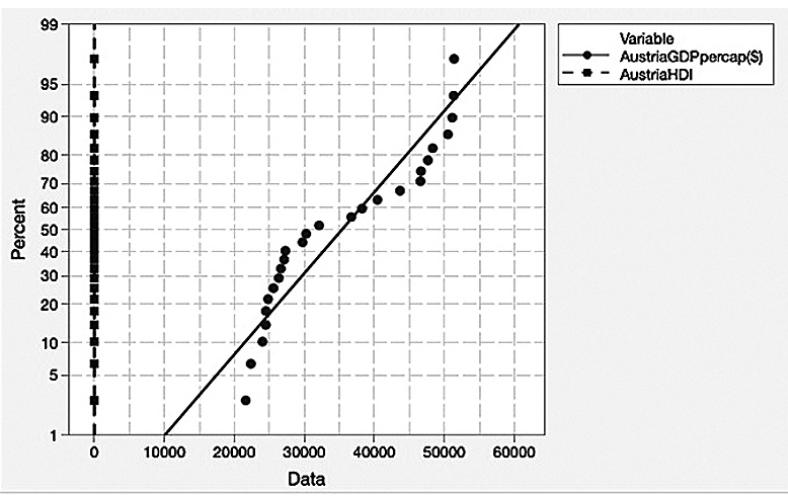

A1(b) Normal Probability Plot of Austria GDP per capita (\$); Austria HDI

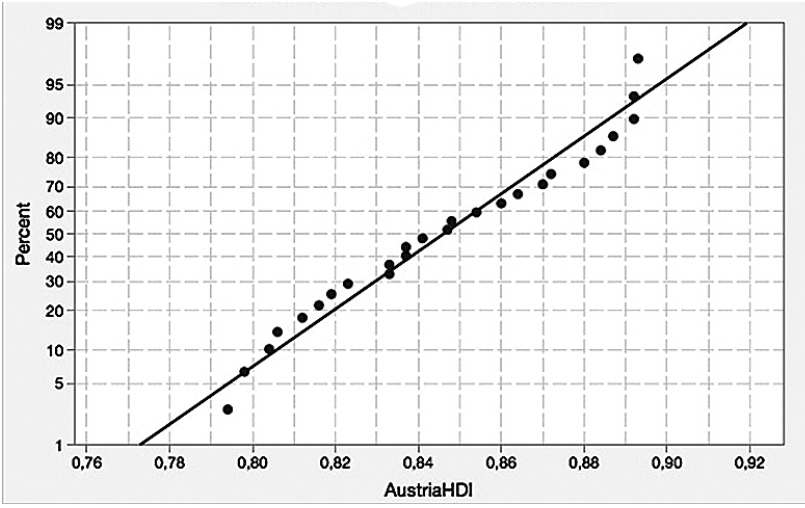

A1(d) Normal Probability Plot of Austria HDI

Figure A1. Descriptive plots of the data (Austria).

Notes:

(a) A sample scatterplot of GDP per capita against the values of HDI based on the data extracted from World Bank (https://data.worldbank.org/indicator/NY.GDP.PCAP.CD?locations=AT) and on Reports of United Nations (http://hdr.undp.org/ en/data) over time for the period covering 27 years from 1990 to a year of 2017.

(b) A sample Normal Probability Plot of GDP per capita and HDI values over the same reporting years (1990-2017) based on the data of GDP per capita for Austria extracted from World Bank dataset (https://data.worldbank.org/indicator/NY.GDP. PCAP.CD?locations=AT) and on the data of HDI for Austria extracted from Human Developments Reports of United Nations (http://hdr.undp.org/en/data).

(c) and (d) Separate Normal Probability plots of GDP per capita and HDI values over a twenty-five year period (1990-2017) (the same data). At the same time, the assumption that non-parametric data of Austria's GDP per capita still provides clear, reliable and relevant descriptive statistics.

income countries, with the high amounts of GDP per capita. Again, this reflects the complexity of permanently patterns of inequality. To conclude, we can see from simply comparing some of the measures of inequality that there are vast differences with regard to income, development and education levels across the world.

\section{Analysis and Results}

When looking at the relationship between two quantitative variables, researchers often hope to find a simple linear relationship. Sometimes the data reveals no relationship or other times a negative relationship. In this essay, let's look at some socioeconomic data of a country. The initial research question with this data is whether the relationship between an economic growth and how the levels of inequality affect it. The data covers 30 selected countries among three groups with regard to the level of development, and the variables are Human Development Index (HDI) values, Gross National Income (GNI) per capita, Education Levels measured by school enrollment ratios and GDP per capita measured in real terms per person. We have divided the three groups of countries by the levels of development i.e., developed countries ( $1^{\text {st }}$ group), developing countries ( $2^{\text {nd }}$ group) and countries of the third 
Table 3

Command output from a simple regression of GDP per capita on HDI values for Austria for the period from 1990 to 2017

\begin{tabular}{|c|c|c|c|c|c|}
\hline \multicolumn{6}{|c|}{ Model Summary } \\
\hline$S$ & \multicolumn{2}{|l|}{ R-sq } & R-sq(adj) & \multicolumn{2}{|c|}{ R-sq(pred) } \\
\hline 4536.05269 & \multicolumn{2}{|c|}{$83.29 \%$} & $82.59 \%$ & \multicolumn{2}{|c|}{$81.01 \%$} \\
\hline \multicolumn{6}{|c|}{ Coefficients } \\
\hline Term & Coef & SE Coef & T-Value & P-Value & VIF \\
\hline Constant & -231253 & 24397 & -9.48 & $<.0001$ & \\
\hline AustriaHDI & 315153 & 28819 & 10,94 & $<.0001$ & 1 \\
\hline & Reg & ression $\mathrm{E}$ & quation & & \\
\hline
\end{tabular}

AustriaGDPpercap $(\$)=-231253+315153$ AustriaHDI

Note. GDP per capita figures extracted from the World Bank (https://data.worldbank.org/indicator/NY.GDP.PCAP. $\mathrm{CD}$ ? locations=AT) and the values of HDI based on the data taken from the Reports of United Nations (http://hdr.undp.org/en/ data) over time for the period covering 27 years from 1990 to a year of 2017.

world ( $3^{\text {d }}$ group). The examples below will use the outputs from Minitab because it is simple and self-documenting.

The following examples (with data from World Bank and United Nations Human Development Reports) represented the analysis of three selected countries, Austria, Mexico and Mozambique, taken from all three groups of countries, in which there are thirty nations in total and covering a twentyseven-year period from 1990 to 2017. Despite the fact that a variety of countries is taken, the reason we present only one per each group is that each category reveals similar patterns and it would be unnecessary to characterize all thirty nations. Thus, instead of it we have selected countries with typical patterns of evaluating history inherent in each group.

\section{Descriptive statistics of Austria}

The scatterplot in figure A1(a) demonstrates that there seems to be a strong positive relationship between these two variables. One way to measure the strength of the relationship is correlation coefficient. For this reason, a Pearson correlation coefficient of Austria's GDP per capita measured in US dollars and HDI values is used where we test whether both variables are correlated. The model exhibits significant correlation of the linear regression model (Regression model: Pearson's $\rho=.9126, p<.0001, N=$ $25)$. However, after running additional tests on normality, Anderson-Darling tests, the data re- vealed that one variable, namely, GDP per capita do not follow normal distribution (AD-value: $1.33, \mathrm{p}=.005)$. This can be visually seen in Figures A1(c) and A1(d). Thus, new Spearman's rank correlation coefficient analysis has been carried out, which is a nonparametric measure of rank correlation. Spearman's $\rho$ indicates that GDP per capita is significantly correlated with inequalityadjusted HDI values ( $\rho=.8733, p<.0001, N=25)$.

Before proceeding to the practical interpretation of the regression coefficients for the linear relationship of GDP per capita and inequalityadjusted HDI values, we would like to remind that regression coefficients present the mean change in the response variable for one unit of change in the predictor variable, meanwhile, holding other predictors in the model constant. Thus, we would like to illustrate this in the scatterplot with a fitted line below, where a Pearson's GDP per capita is used to model their HDI values. First, it is important to consider Minitab's session window output below. The scatterplot with a fitted line in Figure A2(a) illustrates the same regression results graphically.

In this case regression equation is the following. The equation represents that the coefficient for HDI index is 315.153 in US dollars. The coefficient shows that for every additional index can expect GDP per capita to rise by an average of 315.153 US dollars. The R-squired is a statistical measure which tells how close the data are to the fitted regression line. Table 3 demonstrates 


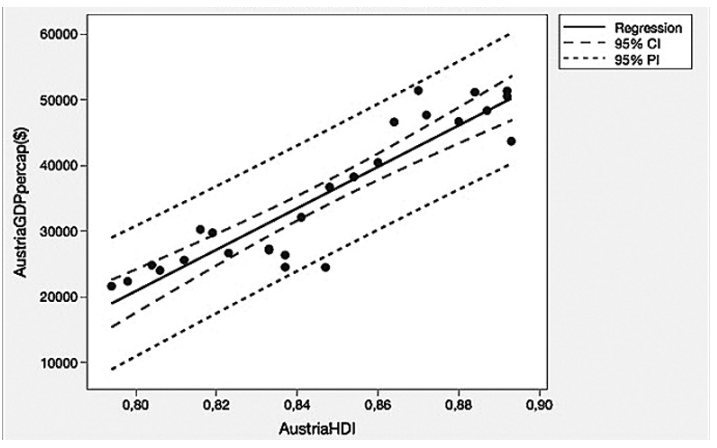

A2(a) Fitted Line Plot for Linear Model

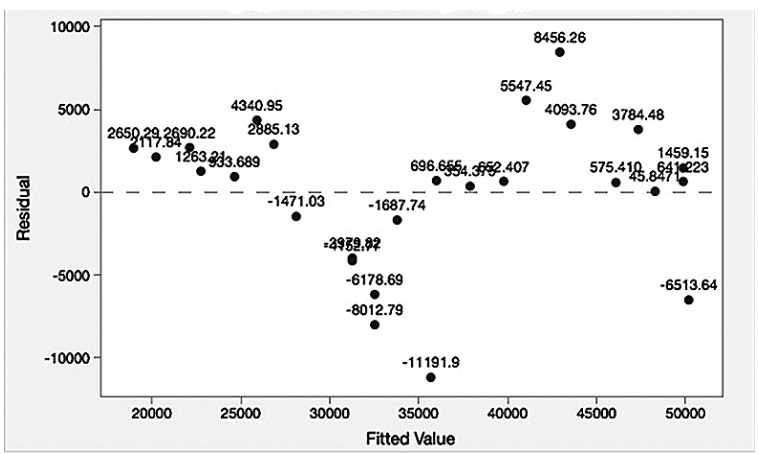

A2(c) Versus Fits (response is Austria GDP per capita (\$))

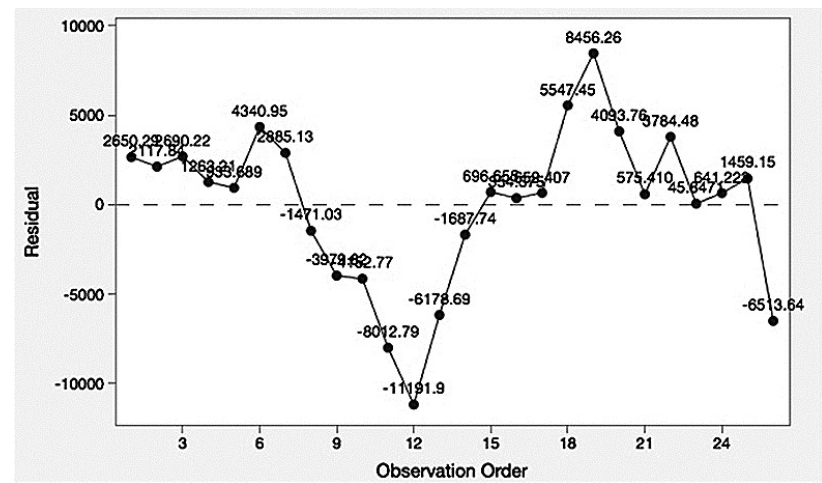

A2(e) Versus Order (response is Austria GDP per capita (\$))

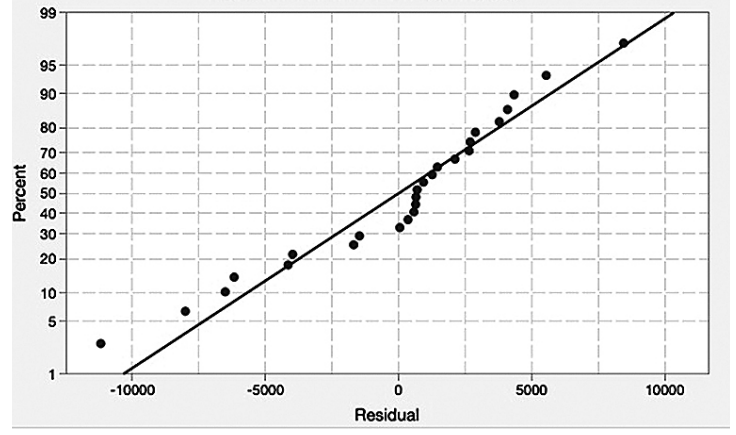

A2(b) Normal Probability Plot (response is Austria GDP per capita (\$))

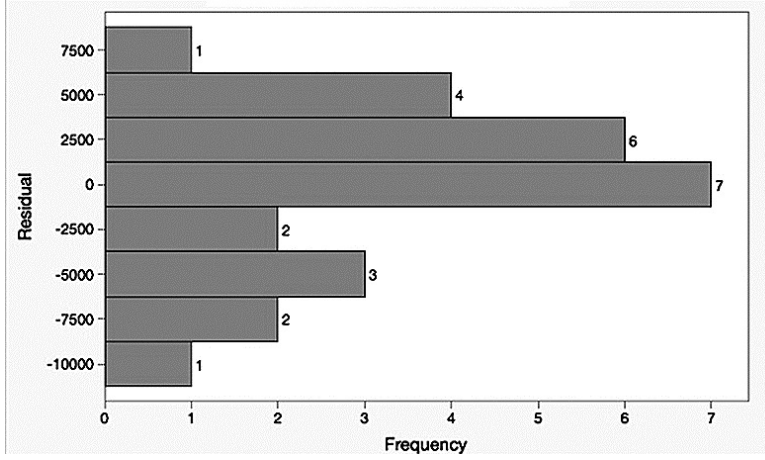

A2(d) Histogram (response is Austria GDP per capita (\$))

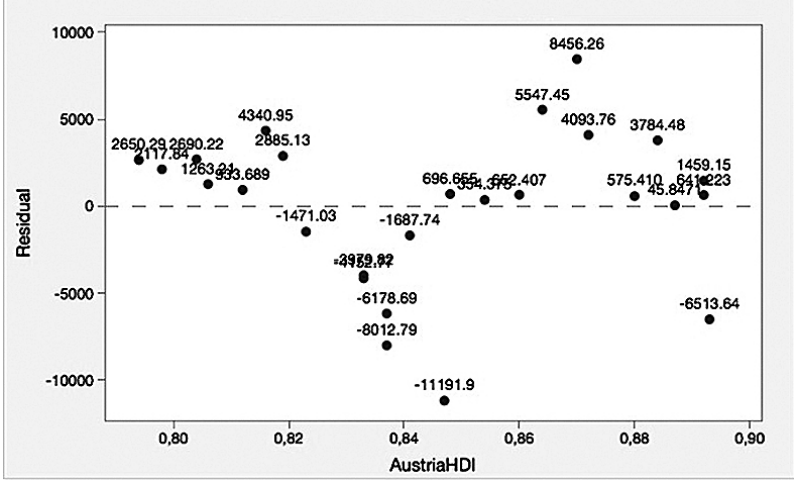

A2(f) Residuals versus Austria HDI (response is Austria GDP per capita (\$))

Figure A2. Descriptive statistics of a simple liner regression of Austria.

Notes:

(a) A sample scatterplot with a fitted line plot of GDP per capita against the values of HDI based on the data extracted from World Bank (https://data.worldbank.org/indicator/NY.GDP.PCAP.CD?locations=AT) and on Reports of United Nations (http://hdr. undp.org/en/data) over time for the period covering 27 years from 1990 to a year of 2017. At the same time, the $95 \%$ confidence and prediction intervals are also displayed.

(b) A sample Normal Probability Plot of Residuals with GDP per capita as a response over the same reporting years (19902017) based on the data of GDP per capita for Austria extracted from World Bank dataset (https://data.worldbank.org/ indicator/NY.GDP.PCAP.CD?locations=AT) and on the data of HDI for Austria extracted from Human Developments Reports of United Nations (http://hdr.undp.org/en/data).

(c) Residual plots versus fits with GDP per capita as a response over a twenty-five-year period (1990-2017) (the same data).

(d) A sample histogram of residuals with GDP per capita as a response over the same reporting years (1990-2017) based on the same data.

(e) A plot of residuals versus order with GDP per capita as a response over the same reporting years (1990-2017) based on the same data.

(f) A plot of residuals versus a separate variable of HDI values. At the same time, the assumption that non-parametric data of Austria's GDP per capita still provides clear, reliable and relevant descriptive statistics. 


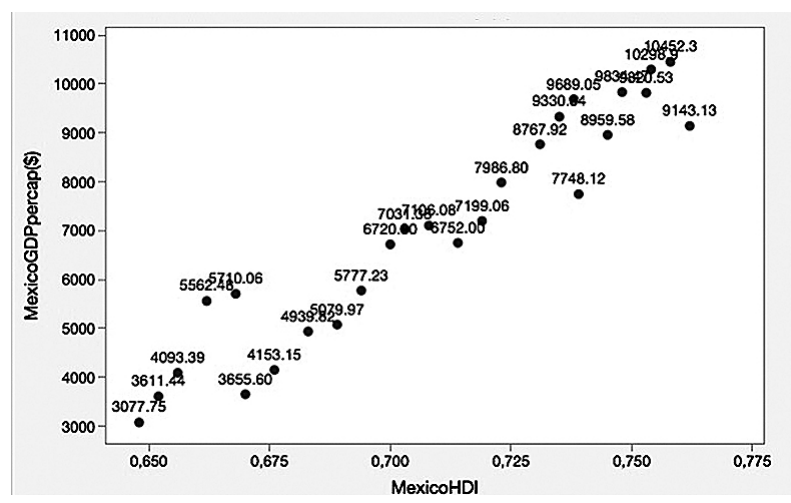

A3(a) Scatterplot of Mexico GDP per cap (\$) vs Mexico HDI

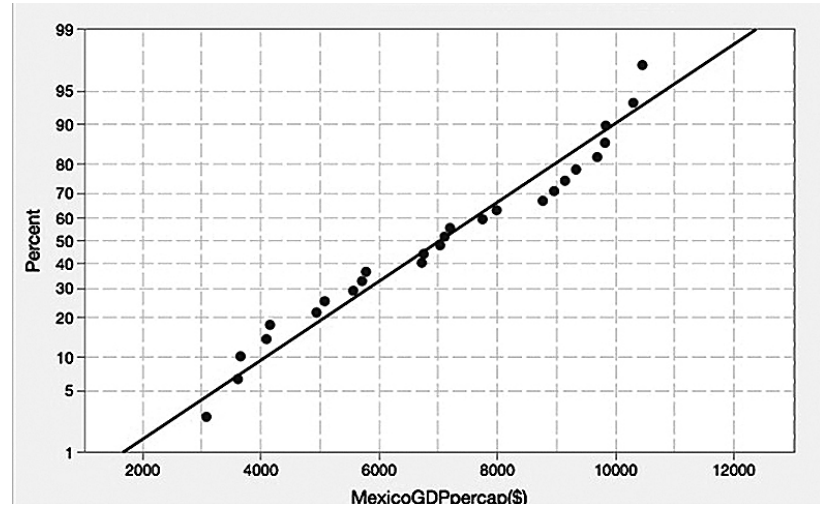

A3(c) Normal Probability Plot of Mexico GDP per cap (\$)

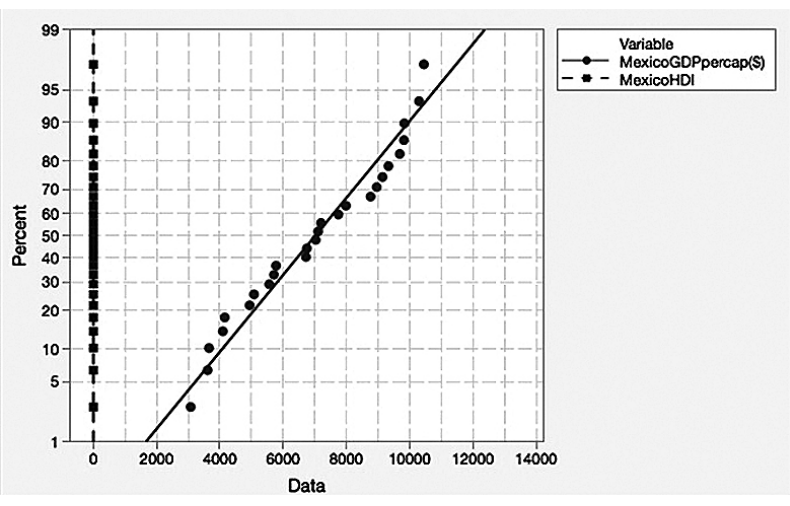

A3(b) Normal Probability Plot of Mexico GDP per cap (\$); Mexico HDI

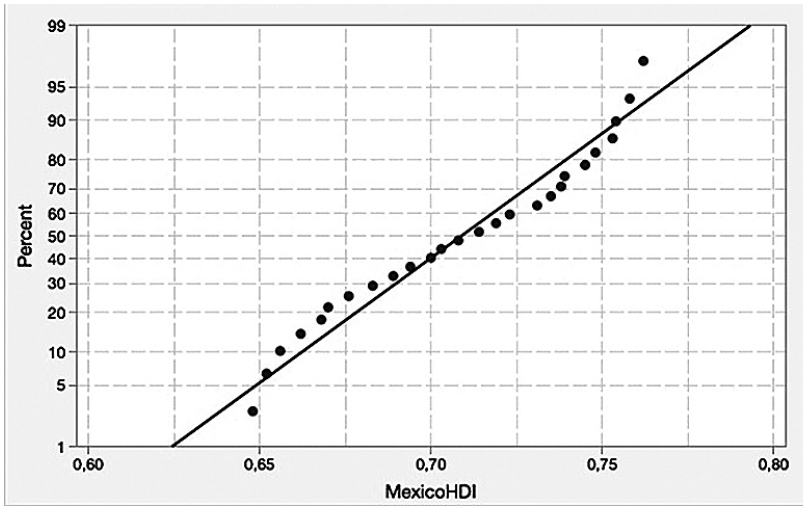

A3(d) Normal Probability Plot of Mexico HDI

Figure A3. Descriptive plots of the data (Mexico).

Notes:

(a) A sample scatterplot of GDP per capita against the values of HDI based on the data extracted from World Bank (https://data.worldbank.org/indicator/NY.GDP.PCAP.CD?locations=MX) and on Reports of United Nations (http://hdr.undp.org/ en/data) over time for the period covering 27 years from 1990 to a year of 2017.

(b) A sample Normal Probability Plot of GDP per capita and HDI values over the same reporting years (1990-2017) based on the data of GDP per capita for Mexico extracted from World Bank dataset (https://data.worldbank.org/indicator/NY.GDP. PCAP.CD?locations=MX) and on the data of HDI for Mexico extracted from Human Developments Reports of United Nations (http://hdr.undp.org/en/data).

(c) and (d) Separate Normal Probability plots of GDP per capita and HDI values over a twenty-five-year period (1990-2017) (the same data).

that the regression model accounts for $82.59 \%$ of the variance.

The presented fitted line in figure A2(a) graphically illustrates the same information. If we move right or left along the $\mathrm{x}$-axis by an amount that represents a one unit change in HDI, the fitted line decreases or increases by 315.153 US dollars. However, these HDIs are for developed countries and range from 0.794 to 0.893 . The relationship is only valid within this data range, so we would not actually shift upward or downward along the line by a full unit of index in this case.

If the fitted line was flat (a slope coefficient of zero), the expected value for GDP per capita would stay unchanged no matter how far we go upward or downward the line. Thus, a very small p-value suggests that the slope is not equal to zero, which subsequently, indicates that changes in the predictor variable are associated with changes in the response variable.

The reason we used a fitted line plot is that it brings math to life. Nevertheless, fitted line scatterplots may only display the results from simple regression, that is to say one predictor variable and the response.

\section{Descriptive statistics of Mexico}

The scatterplot in figure A3(a) demonstrates that there seems to be a strong positive relationship between these two variables. One 
Table 4

Command output from a simple regression of GDP per capita on HDI values for Mexico for the period from 1990 to 2017

Model Summary

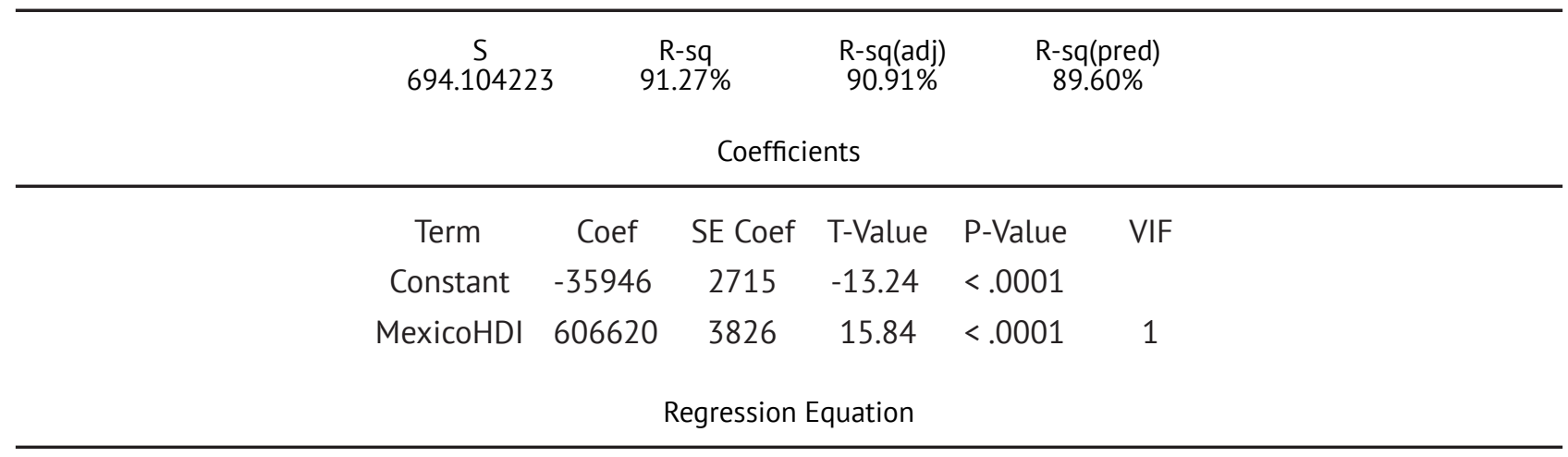

MexicoGDPpercap $(\$)=-35946+606620$ MexicoHDI

Note. GDP per capita figures extracted from the World Bank (https://data.worldbank.org/indicator/NY.GDP.PCAP. $\mathrm{CD}$ ? locations=MX) and the values of HDI based on the data taken from the Reports of United Nations (http://hdr.undp.org/en/ data) over time for the period covering 27 years from 1990 to a year of 2017.

way to measure the strength of the relationship is with correlation coefficient. For this reason, we have run a Pearson correlation coefficient of Mexico's GDP per capita measured in US dollars and HDI values where it is tested whether both variables are correlated with each other. The model exhibits significant correlation of the linear regression model (Regression model: Pearson's $\rho=0.9553, p<$ $.0001, N=25)$. Importantly, after running additional tests on normality, Anderson-Darling Tests, the data revealed that both variables, follow normal distribution (GDP per capita: AD-value: $0.43, p=.2895$; HDI: AD-value: 0.44 , $p=.2623)$. This can be visually seen in figures A3(c) and A3(d).

Before proceeding to the practical interpretation of the regression coefficients for the linear relationship of GDP per capita and inequalityadjusted HDI values, we would like to remind that regression coefficients present the mean change in the response variable for one unit of change in the predictor variable, meanwhile, holding other predictors in the model constant. Thus, let's illustrate this in the scatterplot with a fitted line below, where a Pearson's GDP per capita is used to model their HDI values. First, it is important to consider Minitab's session window output below. The scatterplot with a fitted line in figure A4(a) illustrates the same regression results graphically.
In this case regression equation is the following. The equation represents that the coefficient for HDI index is 606.620 in US dollars. The coefficient shows that for every additional index figure we can expect GDP per capita to rise by an average of 606.620 US dollars. The R-squired is a statistical measure which tells how close the data is to the fitted regression line. Table 4 demonstrates that the regression model accounts for $90.91 \%$ of the variance.

The fitted line in figure A4(a) graphically illustrates the same information. If we move right or left along the $\mathrm{x}$-axis by an amount that represents a one unit change in HDI, the fitted line decreases or increases by 606.620 US dollars. However, these HDIs are for developed countries and range from 0.648 to 0.762 . The relationship is only valid within this data range, so we would not actually shift upward or downward along the line by a full unit of index in this case.

If the fitted line was flat (a slope coefficient of zero), the expected value for GDP per capita would stay unchanged no matter how far you go upward or downward the line. Thus, a very small $\mathrm{p}$-value suggests that the slope is not equal to zero, which subsequently, indicates that changes in the predictor variable are associated with changes in the response variable.

The reason we used a fitted line plot is that it brings the math to life. Nevertheless, fitted line scatterplots may only display the results from 


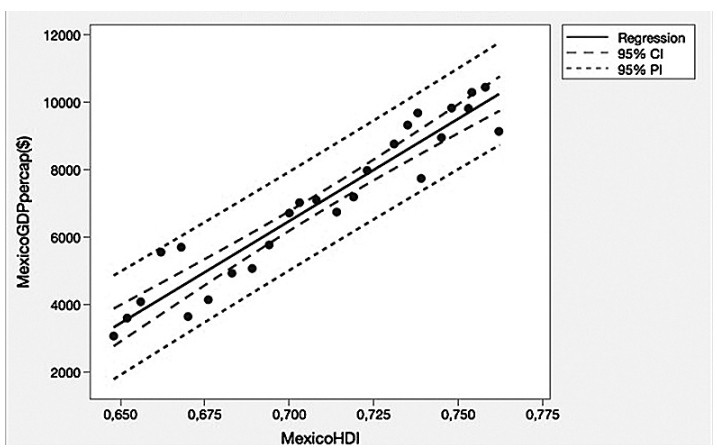

A4(a) Fitted Line Plot for Linear Model

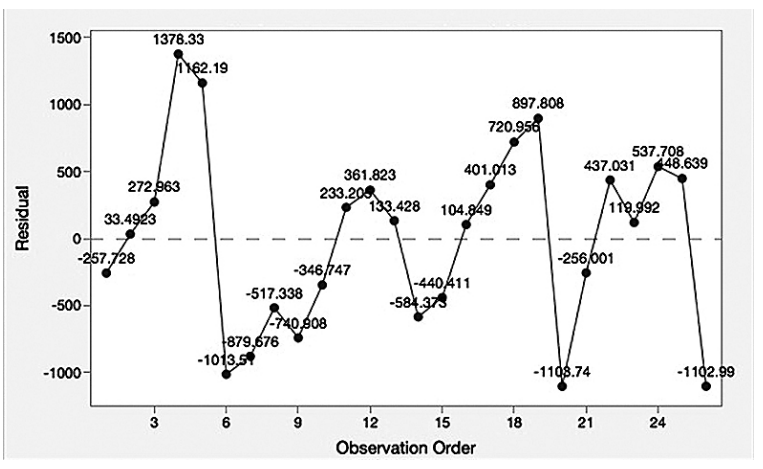

A4(c) Versus Order

(response is Mexico GDP per capita (\$))

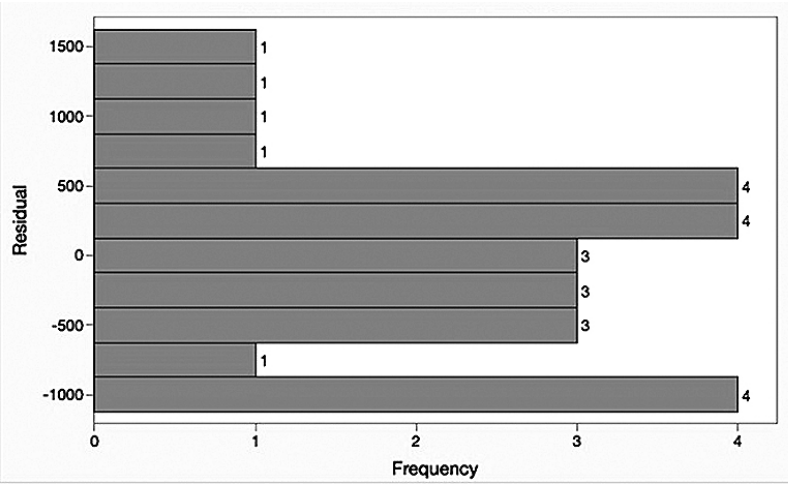

A4(e) Histogram

(response is Mexico GDP per capita (\$))

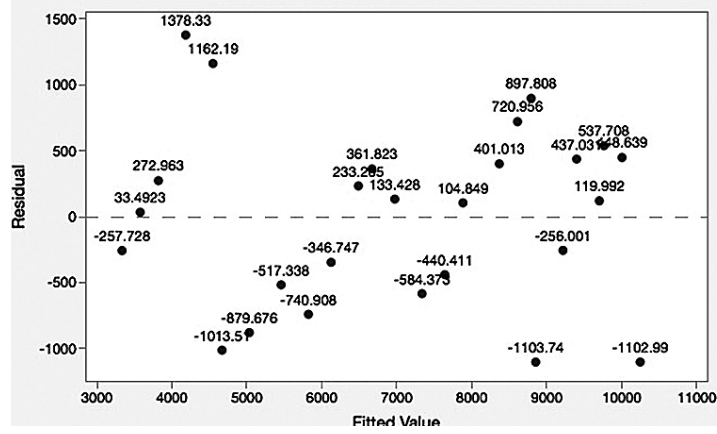

A4(b) Versus Fits

(response is Mexico GDP per capita (\$))

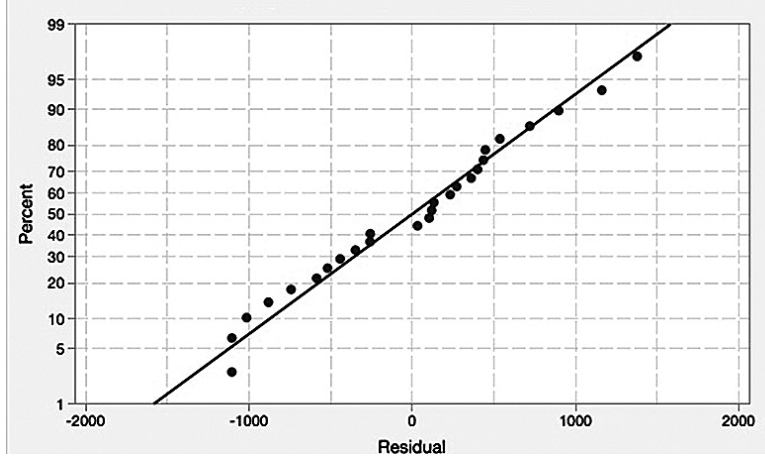

A4(d) Normal Probability Plot (response is Mexico GDP per capita $(\$))$

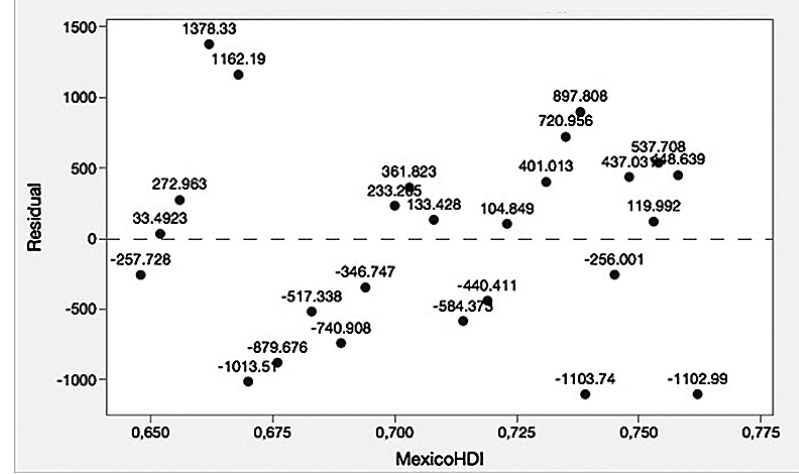

A4(f) Residuals versus Mexico HDI (response is Mexico GDP per capita (\$))

Figure A4. Descriptive statistics of a simple liner regression of Mexico.

Notes.

(a) A sample scatterplot with a fitted line plot of GDP per capita against the values of HDI based on the data extracted from World Bank (https://data.worldbank.org/indicator/NY.GDP.PCAP.CD?locations=MX) and on Reports of United Nations (http://hdr.undp.org/en/data) over time for the period covering 27 years from 1990 to a year of 2017. At the same time, the 95\% confidence and prediction intervals are also displayed.

(b) A sample Normal Probability Plot of Residuals with GDP per capita as a response over the same reporting years (19902017) based on the data of GDP per capita for Mexico extracted from World Bank dataset (https://data.worldbank.org/ indicator/NY.GDP.PCAP.CD?locations=MX) and on the data of HDI for Mexico extracted from Human Developments Reports of United Nations (http://hdr.undp.org/en/data).

(c) Residual plots versus fits with GDP per capita as a response over a twenty-five-year period (1990-2017) (the same data).

(d) A sample histogram of residuals with GDP per capita as a response over the same reporting years (1990-2017) based on the same data.

(e) A plot of residuals versus order with GDP per capita as a response over the same reporting years (1990-2017) based on the same data.

(f) A plot of residuals versus a separate variable of HDI values. 


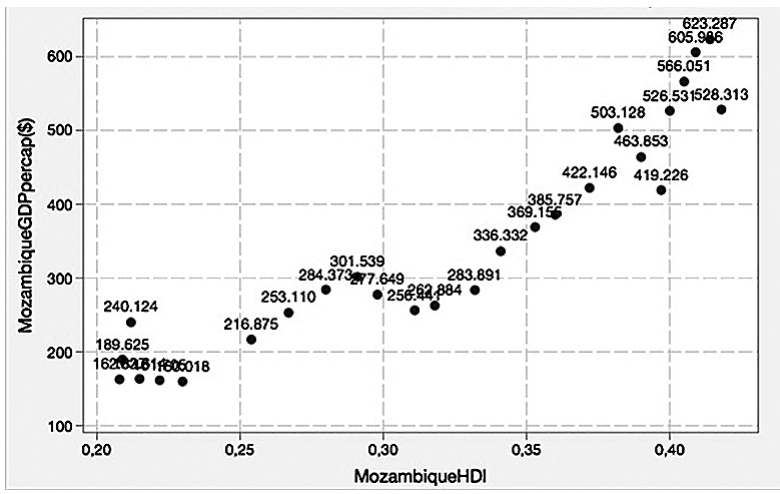

A5(a) Scatterplot of Mozambique GDP per cap (\$) vs Mozambique HDI

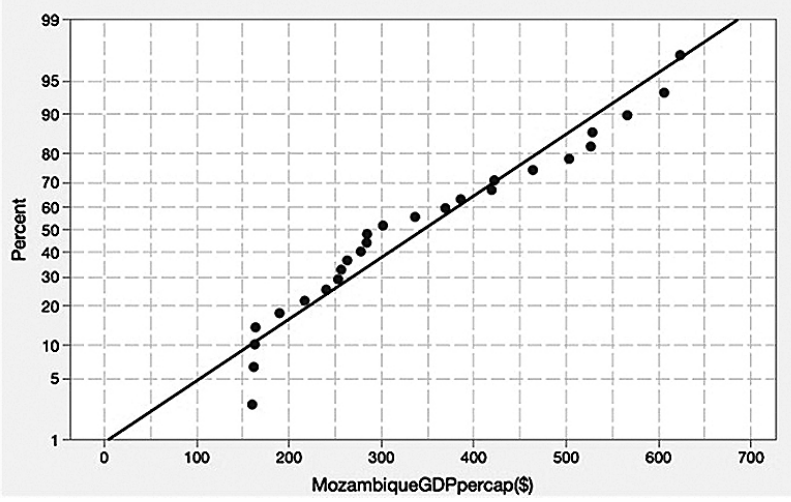

A5(c) Normal Probability Plot of Mozambique GDP per cap (\$)

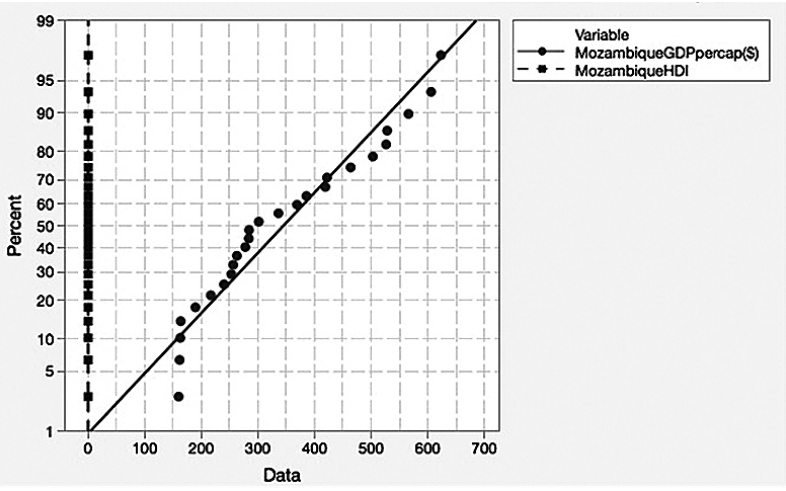

A5(b) Normal Probability Plot of Mozambique GDP per cap (\$); Mozambique HDI

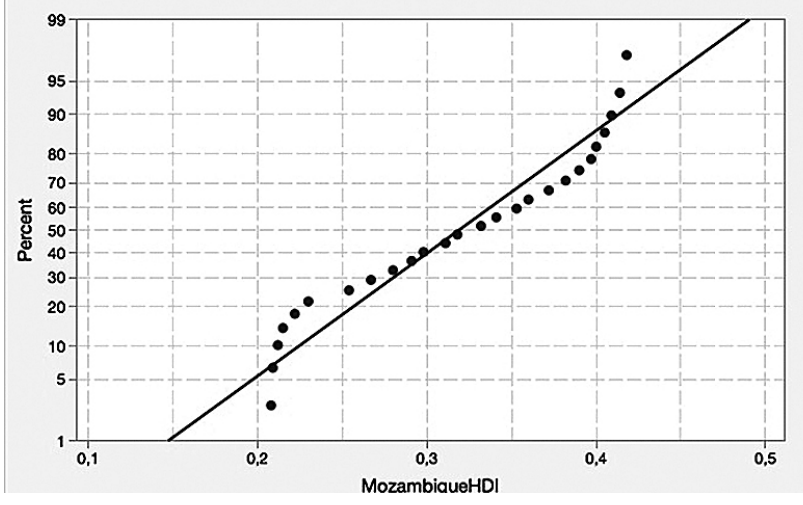

A5(d) Normal Probability Plot of Mozambique HDI

Figure A5. Descriptive plots of the data (Mozambique).

Notes:

(a) A sample scatterplot of GDP per capita against the values of HDI based on the data extracted from World Bank (https://data.worldbank.org/indicator/NY.GDP.PCAP.CD?locations=MZ) and on Reports of United Nations (http://hdr.undp.org/ en/data) over time for the period covering 27 years from 1990 to a year of 2017.

(b) A sample Normal Probability Plot of GDP per capita and HDI values over the same reporting years (1990-2017) based on the data of GDP per capita for Mozambique extracted from World Bank dataset (https://data.worldbank.org/indicator/NY.GDP. PCAP.CD? locations=MZ) and on the data of HDI for Mozambique extracted from Human Developments Reports of United Nations (http://hdr.undp.org/en/data).

(c) and (d) Separate Normal Probability plots of GDP per capita and HDI values over a twenty-five year period (1990-2017) (the same data).

simple regression, that is to say one predictor variable and the response.

\section{Descriptive statistics of Mozambique}

The scatterplot in figure A5(a) also demonstrates that there exists a strong positive relationship between these two variables. One way to measure the strength of the relationship is correlation coefficient. For this reason, we have run a Pearson correlation coefficient of Mozambique's GDP per capita measured in US dollars and HDI values where we test whether both variables are correlated. The model exhibits significant correlation of the linear regression model (Regres- sion model: Pearson's $\rho=0.9334, p<.0001, N=$ 25). Importantly, after running additional tests on normality, Anderson-Darling tests, the data revealed that both variables, follow normal distribution (GDP per capita: AD-value: $0.63, p=$ .0900; HDI: AD-value: 0.68, $p=.0666$ ). This can be visually seen in figures A5(c) and A5(d).

Thus, as usual, before proceeding to the practical interpretation of the regression coefficients for the linear relationship of GDP per capita and inequalityadjusted HDI values, we would like to illustrate this in the scatterplot with a fitted line below, where we are going to use a Pearson's GDP per capita to model their HDI values. First, it is important to consider 


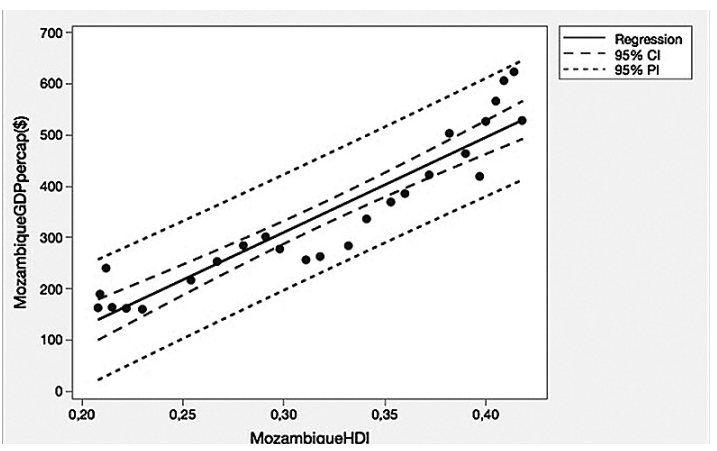

A6(a) Fitted Line Plot

for Linear Model

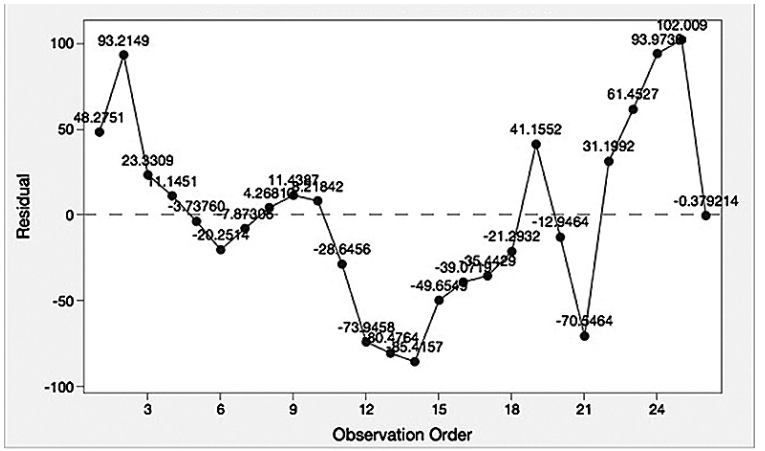

A6(c) Versus Order (response is Mozambique GDP per cap $(\$))$

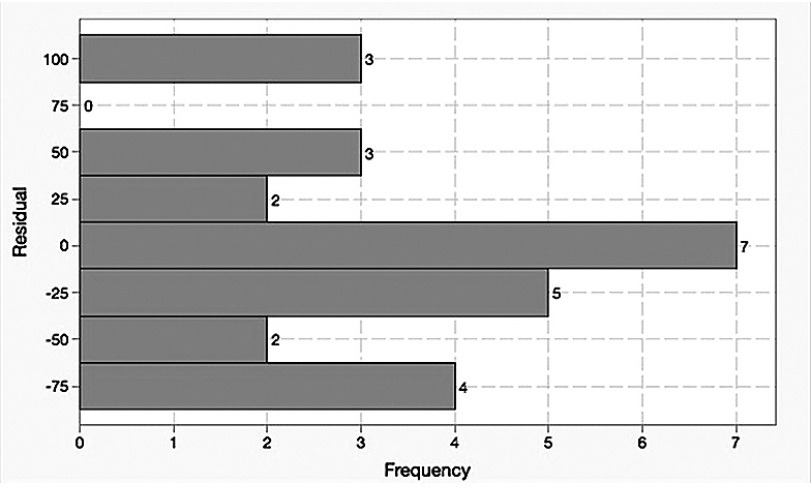

A6(e) Histogram

(response is Mozambique GDP per cap (\$))

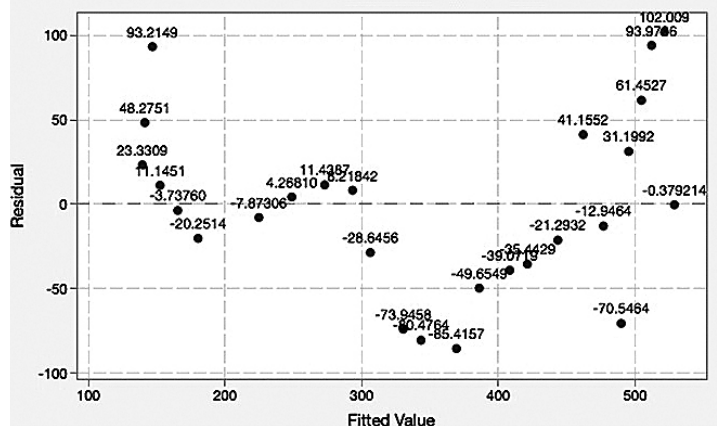

A6(b) Versus Fits (response is Mozambique GDP per cap (\$))

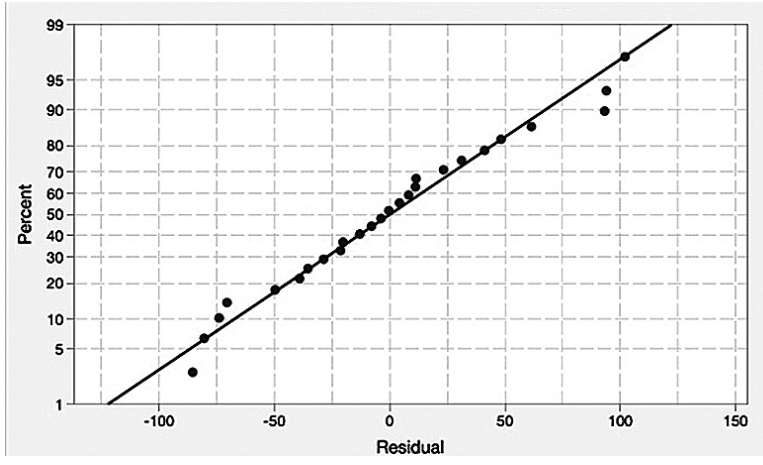

A6(d) Normal Probability Plot (response is Mozambique GDP per cap (\$))

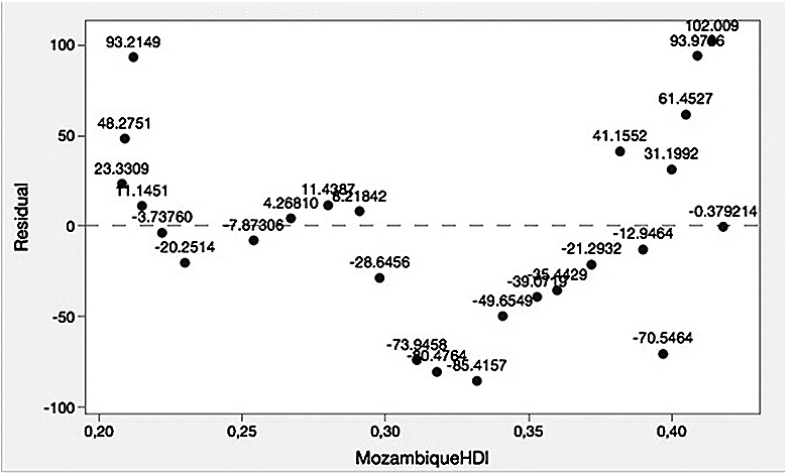

A6(f) Residuals versus Mozambique HDI (response is Mozambique GDP per cap (\$))

Figure A6. Descriptive statistics of a simple liner regression of Mozambique.

Notes:

(a) A sample scatterplot with a fitted line plot of GDP per capita against the values of HDI based on the data extracted from World Bank (https://data.worldbank.org/indicator/NY.GDP.PCAP.CD?locations=MZ) and on Reports of United Nations (http://hdr.undp.org/en/data) over time for the period covering 27 years from 1990 to a year of 2017. At the same time, the 95\% confidence and prediction intervals are also displayed.

(b) A sample Normal Probability Plot of Residuals with GDP per capita as a response over the same reporting years (19902017) based on the data of GDP per capita for Mozambique extracted from World Bank dataset (https://data.worldbank.org/ indicator/NY.GDP.PCAP.CD?locations=MZ) and on the data of HDI for Mozambique extracted from Human Developments Reports of United Nations (http://hdr.undp.org/en/data).

(c) Residual plots versus fits with GDP per capita as a response over a twenty-five year period (1990-2017) (the same data).

(d) A sample histogram of residuals with GDP per capita as a response over the same reporting years (1990-2017) based on the same data.

(e) A plot of residuals versus order with GDP per capita as a response over the same reporting years (1990-2017) based on the same data.

(f) A plot of residuals versus a separate variable of $\mathrm{HDI}$ values. 
Command output from a simple regression of GDP per capita on HDI values for Mexico based on a period from 1990 to 2017

Model Summary

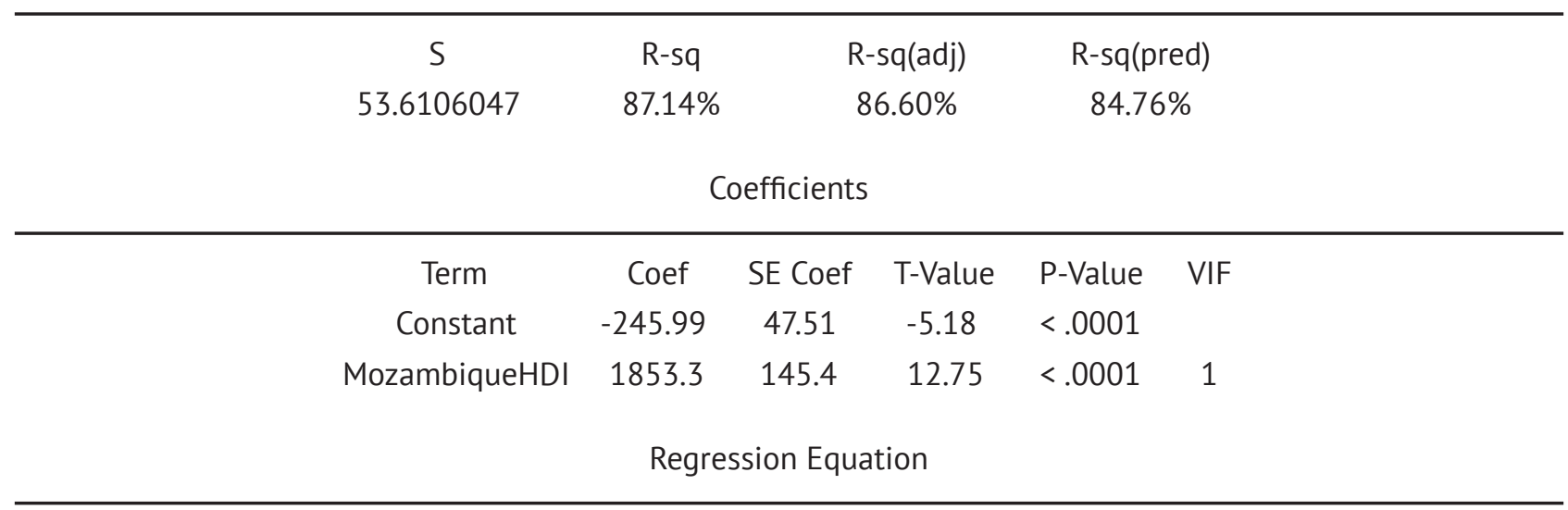

MozambiqueGDPpercap(\$) = -245.99 + 1853.3 MozambiqueHDI

Note. GDP per capita figures extracted from the World Bank (https://data.worldbank.org/indicator/NY.GDP.PCAP. $\mathrm{CD}$ ? locations=MZ) and the values of HDI based on the data taken from the Reports of United Nations (http://hdr.undp.org/en/ data) over time for the period covering 27 years from 1990 to a year of 2017.

Minitab's session window output below. The scatterplot with a fitted line in figure A6(a) illustrates the same regression results graphically.

In this case regression equation is the following. The equation represents that the coefficient for HDI index is $1,853.3$ in US dollars. The coefficient shows that for every additional index figure we can expect GDP per capita to rise by an average of $1,853.3$ US dollars. The R-squired is a statistical measure which tells how close the data is to the fitted regression line. Table 5 demonstrates that the regression model accounts for $84.76 \%$ of the variance.

The fitted line in figure A6(a) graphically illustrates the same information. If we move right or left along the $\mathrm{x}$-axis by an amount that represents a one unit change in HDI, the fitted line decreases or increases by 1853.3 US dollars. However, these HDIs are for developed countries and range from 0.209 to 0.418 . The relationship is only valid within this data range, so we would not actually shift upward or downward along the line by a full unit of index in this case.

If the fitted line was flat (a slope coefficient of zero), the expected value for GDP per capita would stay unchanged no matter how far you go upward or downward the line. Thus, a very small $\mathrm{p}$-value suggests that the slope is not equal to zero, which subsequently, indicates that changes in the predictor variable are associated with changes in the response variable.

\section{Conclusions}

After carrying out statistical analysis, let's confirm that inequality slows economic growth. Low-income countries associated with high levels of inequality tend to grow more slowly in economic terms. Our findings are supported by the similar results of Ortiz and Cummins (2011). Thus, economic growth is mostly associated with countries characterized by well-developed economic policy, which supports and promotes free trade. It can lead to economic growth and, subsequently, to poverty reduction.

In other words, increasing wealth is seen to decrease poverty. However, based on some relevant studies, there is a contradictory evidence in relation to this that economic growth does not automatically result in reduced levels of inequality; rather it is considered to be a main factor in enriching the rich and further impoverishing the poor.

According to the study by World Bank (World Development Report, 2017), inequality can slow economic growth and therefore be seen as negative by economists. Economic growth itself is unlikely to result in poverty reduction. From our opinion, it is incorrect to fully ignore economic growth.

We strongly believe, and support the opinion by analytical data, that economic growth is the main stimulator of the level of inequality. That is to say, if a nation is wealthy enough, the society in it will live in prosperity. 


\section{References}

Firebaugh, Glenn. (2004). Does industrialization no longer benefit poor countries? A comment on Arrighi, Silver, and Brewer. Studies in Comparative International Development, 39(1), 99-105. Retrieved from http://sites.jmu.edu/ benbrewer/files/2011/01/SCID-Firebaugh.pdf.

Human Development Data (1990-2015). Human Development Reports. United Nations Development Programme. Retrieved from http://hdr.undp.org/en/data.

Milanovic, Branko, Lindert, Peter, \& Williamson, Jeffrey. (2007, October). Measuring Ancient Inequality. National Bureau of Economic Research. MPRA Paper No. 5388. Retrieved from https://mpra.ub.uni-muenchen.de/5388/1/ MPRA_paper_5388.pdf

Milanovic, Branko, Lindert, Peter H., \& Williamson, Jeffrey G. (2010). Pre-Industrial Inequality. The Economic Journal, 121 (March), 255-272. doi:10.1111/j.1468-0297.2010.02403.x. Retrieved from https://gc.cuny.edu/CUNY_GC/ media/CUNY-Graduate-Center/PDF/Centers/LIS/Milanovic/papers/2011/MLW_final.pdf.

Ortiz, Isabel, \& Cummins, Matthew. (2011). Global Inequality: Beyond the Bottom Billion. A Rapid Review of Income Distribution in 141 Countries. United Nations Children's Fund (UNICEF). Retrieved from https://www.unicef.org/ socialpolicy/files/Global_Inequality.pdf.

Sen, A. (1999). Development as freedom. Oxford, England: Oxford University Press. Retrieved from http://www.c3l. uni-oldenburg.de/cde/OMDE 625/Sen/Sen-intro.pdf.

World Bank Open Data. World Bank. Retrieved from https://data.worldbank.org.

World Development Report 2017. Governance and the Law. (2017). Washington, DC: The World Bank. Retrieved from http://www.worldbank.org/en/publication/wdr2017.

World Population Ageing 2009. (2009). ESA/P/WP/212. New York, NY: United Nations. Retrieved from http://www. un.org/esa/population/publications/WPA2009/WPA2009_WorkingPaper.pdf.

World Population Ageing Report 2015 [Report]. (2015). ST/ESA/SER.A/390. New York, NY: United Nations. Retrieved from http://www.un.org/en/development/desa/population/publications/pdf/ageing/WPA2015_Report.

World Urbanization Prospects. The 2007 Revision. Highlights. (2008). New York, NY: United Nations. Retrieved from http://www.un.org/esa/population/publications/wup2007/2007WUP_Highlights_web.

\section{Стимулирует ли социальное неравенство экономический рост?}

(на примерах выбранных развивающихся стран)

$$
\text { Алина Пухаева }{ }^{1} \text {, Елена Мирошина (Силантьева) }{ }^{2}
$$

В статье критически рассматривается концепция социального неравенства и предлагаются способы ее определения на фоне широкого спектра факторов, определяющих неравенство среди самых богатых и беднейших стран. В ней также содержатся обобщенные показатели неравенства между тремя группами стран путем сопоставления некоторых макроэкономических показателей социально-экономического неравенства. Затем мы проверили наличие линейной зависимости между двумя количественными переменными. Используя данные Всемирного банка и докладов Организации Объединенных Наций по человеческому развитию, мы провели анализ отдельных стран, взятых из трех групп стран (всего тридцать стран), за период с 1990 по 2017 год. После проведения статистического анализа мы доказали, что неравенство замедляет экономический рост.

Ключевые слова: неравенство; доход; ВBП на душу населения; бедность; HDI

JEL classification: I31, J11, J24, D63

\footnotetext{
1 Международный финансовый факультет, Финансовый университет, Москва, Россия; alexandra.puhaeva@ gmail.com

${ }^{2}$ Кандидат экономических наук, Департамент мировой экономики и мировых финансов, Финансовый университет, Москва, Россия; EAsila@yandex.ru
} 